\title{
UMA ANTROPOLOGIA HISTÓRICA DA GRÉCIA ANTIGA: GERNET E A REINVENÇÃO DURKHEIMIANA DOS ESTUDOS HELÊNICOS ${ }^{1}$
}

Fábio Vergara Cerqueira*

Recebido em: 22/03/2019

Aprovado em: 28/04/2019

RESUMO: Em 2017 completou-se o centenário da publicação da tese de doutorado de Louis Gernet, defendida em Paris, intitulada Recherches sur le développement de la pensée juridique et morale en Grèce. Obra inicialmente rejeitada pelo stablishment acadêmico francês, condenando seu autor à marginalidade intelectual, hoje é considerada um turning point nos estudos helênicos, como obra fundante da assim chamada Antropologia histórica da Grécia antiga ou, simplesmente, Antropologia da Grécia antiga. Nosso objetivo neste artigo será analisar a influência, sobre sua obra, da sociologia de Émile Durkheim e de sua escola, possibilitando a reinvenção dos estudos helênicos por parte de Gernet, com a superação dos paradigmas do século XIX, do evolucionismo positivista e do idealismo eurocêntrico inspirado no mito do "milagre grego". Essa influência pode ser verificada sobretudo no papel conferido por Gernet à permanência dos elementos religiosos.

PALAVRAS-CHAVE: Louis Gernet; Antropologia da Grécia antiga; Antropologia histórica; Émile Durkheim.

\footnotetext{
${ }^{1}$ Para a elaboração deste artigo, estimulado pelo centenário da defesa da tese de doutorado de Louis Gernet, em 2017, retomei, sob novo olhar, dois escritos meus mais antigos: 1) o artigo "Algumas considerações sobre a cidade antiga grega na obra de Louis Gernet", Anais do III Simpósio de História Antiga, Porto Alegre, UFRGS, 1989, p. 193-219, e 2) a monografia “A influência de Émile Durkheim e da escola sociológica francesa sobre Louis Gernet e sobre a Antropologia da Grécia Antiga: a formação da antropologia histórica nos Estudos Clássicos" (trabalho para a disciplina "Teorias Antropológicas Clássicas, Programa de Pós-Graduação em Antropologia Social, USP, 1996, 17 p.). Esta pesquisa conta com o apoio do CNPq, da CAPES e da Fundação Humboldt.
}

*Professor Titular do Departamento de História, UFPel.

Pesquisador CNPq PQ-1d em Arqueologia. Humboldt-Foundation Fellow, Alemanha. Pesquisador Visitante, Instituto de Arqueologia Clássica, Universidade de Heidelberg.

fabiovergara@uol.com.br 


\title{
HISTORICAL ANTHROPOLOGY OF ANCIENT GREECE: GERNET AND THE DURKHEIMIAN REINVENTION OF HELLENIC STUDIES
}

\begin{abstract}
In 2017 the Recherches sur le développement de la pensée juridique et morale en Grèce, doctorate dissertation of Louis Gernet defended in Paris, completed its centenary. A work initially rejected by the French academic stablishment, condemning its author to the intellectual marginality, today it is considered a turning point in the Hellenic studies, as the founding work of the so-called Historical Anthropology of Ancient Greece or, simply, Anthropology of Ancient Greece. In this article, we aim to analyze the influence on his work of the Sociology of Émile Durkheim and his school, as the basis for his reinvention of the Hellenic Studies, with the overcoming of the nineteenth century positivist evolutionism and Eurocentric idealism inspired by the myth of "Greek Miracle". This influence can be seen mainly in the role given by Gernet to the permanence of religious elements.
\end{abstract}

KEYWORDS: Louis Gernet; Anthropology of Ancient Greece; Historical Anthropology; Émile Durkheim.

Élève de Durkheim, ami de Mauss et de Granet, Louis Gernet est en France le premier à avoir abordé l'étude des civilisations anciennes dans une perspective sociologique ou, pour mieux dire, anthropologique (Jean-Pierre Vernant, 1962) ${ }^{2}$

\section{INTRODUÇão}

$\mathrm{N}$ o ano de 2017 completou-se o centenário de um dos textos mais importantes do século XX no campo dos estudos da Grécia antiga, apesar de ter sido alvo de "rejeição total na linguagem e no método", pois "o helenismo não admitia a sociologia no seu domínio espiritual” (Donato, 1983, p. 409). Um texto que foi, a meu ver, a base de uma das maiores guinadas dos estudos da Antiguidade grega, mesmo que esta não tenha se dado de forma direta e imediata, tendo em vista que seu autor, Louis Gernet (18821962), não foi bem compreendido a seu tempo e durante algumas décadas viveu uma espécie de exílio intelectual, lecionando em Argel entre 1921 e 1948, o que minimizou por um bom tempo seu potencial para influenciar os novos helenistas em formação na França. Trata-se da sua tese de doctorat ès lettres, intitulada Recherches sur le développement de la pensée juridique et morale en Grèce ("Pesquisas sobre o desenvolvimento do pensamento jurídico e moral na

\footnotetext{
${ }^{2}$ Meu especial agradecimento à Dra. Loiva Otero Félix, professora e orientadora na Graduação em História (UFRGS), que indicou em meus primeiros anos de estudo a leitura de Louis Gernet, responsável por despertar em mim uma visão antropológica da Antiguidade grega. Agradeço ainda a Eduardo Christmann pelo apoio como bolsista de Iniciação Científica (CNPq).
} 
Grécia"), que, na esteira de Fustel de Coulanges (1830-1889) e Gustave Glotz (1862-1935), elege o estudo do direito como um dos elementos centrais para se compreender a cidade antiga. Diferentemente destes, porém, vai além do plano da institucionalidade, imergindo no pensamento e na psicologia social, através da linguagem e da semântica, de um modo que de certa maneira antecipa estudos que se farão décadas mais tarde sob a denominação de história das mentalidades, imaginário ou representações. Como coloca Sally Humphreys, ao reconhecer seu lugar na edificação de uma Antropologia da Grécia antiga, "o estudo do seu tratamento do mito grego, da religião e das instituições sociais mostra que ele foi um pioneiro na abordagem estruturalista dada à semântica e ao estudo do mito como uma forma de linguagem" (Humphreys, 1971, p. 172). ${ }^{3}$

Entre sua produção, além da mencionada tese de doutorado de 1917, podemos destacar: sua obra coautoral, Le génie grec dans la religion, de 1932, assinada também por André Boulanger (1886-1958), publicada na coleção L'Évolution de l'Humanité, talvez o único momento de maior visibilidade na academia francesa ao longo de seus 27 anos de ostracismo no Norte da África; Droit et prédroit en Grèce ancienne (1951) e Droit et société dans la Grèce ancienne (1955), publicadas pelo Instituto de Direito Romano da Universidade de Paris, onde, nos anos 50, encontrou um terreno fértil e acolhedor para partilhar suas reflexões sobre sua antropologia do Direito grego; a coletânea póstuma editada por François Maspero, em 1968, sob o título Anthropologie de la Grèce antique, composta de cinco partes (Religion et Société, Formes de la pensée mythique, Philosophie et Société, e Droit et Institutions en Grèce antique), baseada em um dossiê preparado por Gernet pouco antes de falecer, que já estava corrigido e revisado, e foi encontrado por Vernant em seus arquivos pouco após sua morte (Vernant, 1983, p. 9-10); e, finalmente, Les grecs sans miracle, coletânea de textos, muitos deles até então inéditos, organizada por Riccardo di Donato e publicada pela La Découverte-Maspero em 1983, com prefácio de Vernant e posfácio do próprio Donato, em que retoma e revisa seu artigo do ano anterior, "L'anthropologie historique de Louis Gernet", publicado nos Annales.

Marginalizado no métier acadêmico por quase três décadas, houve que se esperar sua morte para que o papel de Louis Gernet pudesse ser devidamente apreciado, permitindo compreender a inestimável e insubtraível contribuição desse pensador ao avanço dos estudos helênicos. Segundo Vernant (1983), sua obra foi a responsável pela passagem operada do humanismo tradicional (aquele do "milagre grego"), que se emocionava ao ver aquilo que os gregos "já conheciam", para uma Antropologia histórica. Fazendo objeto de seu estudo o "homem" da Grécia antiga, suas formas de pensamento e de sociedade, e negando todos os $a$ priori do Classicismo, fundou, como o quer Donato (1983, p. 403), a "Ciência da Antiguidade".

\footnotetext{
3 "Study of his treatment of Greek myth, religion, and social institutions shows him to have been a pioneer in the structuralist approach to semantics and the study of myth as a form of language". ${ }^{4}$ As duas últimas partes da coletânea, "Droit" e "Institutions en Grèce antique", compõem o livro Droit et Institutions en Grèce Antique, publicado em 1982 pela editora Flammarion. Na publicação da Maspero, além dos textos selecionados pelo próprio Gernet, Vernant (1983, p. 11) propôs ao editor "ampliar o projeto, incluindo toda uma série de outros artigos que Gernet tinha publicado em revistas de pouca circulação e que [lhe] pareciam próprios para serem mais bem conhecidos através de uma coletânea". ${ }^{5}$ Donato, 1982, p. $984-96$.
} 
Entre o Gernet historiador, o sociólogo, o antropólogo, o jurista, o linguista e o filólogo - e ainda o interessado por psicologia social - encontra-se um ponto de intersecção que é o helenista Louis Gernet. Um helenista rebelde, podemos dizer, que pensa na Grécia antiga a partir deste lugar privilegiado de uma interdisciplinaridade alimentada pelas renovações da virada de século, que ocorrem nas humanidades e áreas afins (ex. linguística e psicologia). Essas renovações tornavam possíveis olhares contestadores para uma nova e inquieta geração de intelectuais franceses das primeiras décadas do século passado. Reinava uma epistemologia positivista, evolucionista e classicista, hegemônica por algumas décadas nas universidades francesas, que lhes angustiava, e contra a qual abriram dissidência.

Gernet elege o Direito grego para, a partir dele - através de um estudo semântico que pensa o devir do pensamento embaralhado ao devir das instituições jurídicas -, produzir um entendimento da Antiguidade grega simultaneamente baseado no universo representacional e institucional. Enquanto sociólogo, recebe suas influências iniciais de Émile Durkheim (1858-1917) e Marcel Mauss (1872-1950); enquanto filólogo, recusa o positivismo alemão oitocentista, preferindo um estudo em que as variações dos sentidos das palavras apareçam como uma relação ativa e dinâmica entre língua e sociedade, baseado em Antoine Meillet. Propõe, então, uma filologia “deveras filológica” (Gernet, 1917, p. X), em que a linguagem apareça como depósito de pensamento moral, enquanto fato social, cuja compreensão permita iluminar uma realidade psicológica coletiva, pela qual já se perguntava em uma monografia que escreveu sobre a moeda aos 21 anos, em 1903, em seu segundo ano na École Normale Supérieure. ${ }^{6}$

Na perspectiva aberta por Gernet, a palavra - o vocabulário e sua semântica estudados numa perspectiva histórica - era a chave de interpretação da "unidade da consciência coletiva". $\mathrm{Na}$ passagem a seguir, nosso autor torna claro por que elege a língua como instrumento para a pesquisa sobre o passado grego: "ela traduz ideias e sentimentos comuns a tudo que faz parte da vida de um grupo, e que se podem considerar de igual forma nas instituições como nas consciências" (Gernet, 1917, p. VIII). ${ }^{7}$

O objetivo de Gernet, como o expressa Vernant (1983), é entender a passagem de uma Grécia da "pré-história" (do "Pré-direito") a uma Grécia da cidade (do "Direito"), enfim, da ordem clânica à pólis, com o advento de fenômenos como o Direito, a moeda, a instituição política, a emergência de uma ética, a nascença da Filosofia, da História, da Ciência e da tragédia, numa leitura em que se visualize a transição intelectual de um pensamento mítico-religioso a uma inteligência crítica, racional, sem cair porém na armadilha de uma ilusão evolucionista, visto que pressupõe a constante renovação e permanência do "velho" no "novo".

\footnotetext{
${ }^{6}$ Em seu mémoire de license sobre a moeda, cujos manuscritos Gernet guardava em seus arquivos pessoais, ele falava de "psicologia social que substitui a psicologia individual na interpretação dos fatos sociais" (Archives Louis Gernet, apud Donato, 1983, p. 408, n. 21).

7 "Ce sont des idées et des sentiments comuns à tous qui entretiennent la vie d'un groupe, et qui peuvent considérer aussi bien dans les institutions que dans les consciences”.
} 
Assim, para entender a guinada antropológica da Grécia de Gernet, é preciso vislumbrar como se deu a influência da Antropologia francesa do início do século XX em sua fase de formação intelectual e como esses conceitos se cristalizaram em sua obra como chaves de interpretação. ${ }^{8}$ Neste artigo, será analisada em especial a influência de Émile Durkheim sobre a formação do jovem Gernet e sobre a genealogia de sua obra.

Seguramente, Durkheim não é a única influência teórica que conta. Não menos importante é o interesse especial de Gernet pela psicologia social (que evolui para o interesse por uma psicologia coletiva, e nos anos 20 para uma psicologia histórica) e pela semântica histórica ${ }^{9}$ - interesses que o acompanham desde os primeiros anos de sua vida intelectual, inclusive presentes na elaboração de seu projeto de tese de doutorado apresentado à Fundação Thiers (Donato, 1983; Corrêa, 2010, p. 4). Como sintetiza André Davidovitch (1962, p. 329) sobre a obra de Gernet, "a linguística era um dos elementos do método sociológico de Louis Gernet e sem dúvida, reciprocamente, a sociologia um dos elementos de seu método linguístico". ${ }^{10}$

No entanto, seja sobre ele individualmente, seja sobre a rede de jovens pensadores franceses com a qual o Gernet da juventude convive e atua, a influência de Émile Durkheim é preponderante. No caso de Gernet, o fator religioso, como o compreende a partir da sociologia durkheimiana, funcionou como base conceitual e metodológica para romper com o mito do "milagre grego". Como ele mesmo admite, "quanto à inspiração geral, é quase supérfluo dizer agora: nós a devemos aos escritos do senhor Durkheim e de sua escola" (Gernet, 1917, p. XVIII). ${ }^{11}$

\footnotetext{
${ }^{8}$ Entre os textos citados na bibliografia, destaco os que mais especialmente contribuíram para este artigo: Recherches sur le développement de la pensée juridique et morale en Grèce, publicado em 1917 por Ernest Leroux e reeditado pela Albin Michel em 2002; Droit et ville dans l'Antiquité grecque, publicado originalmente em 1957, e republicado pela Maspero em 1968 e pela Flammarion em 1982; "Constitution et religion" e "Les bases de la cité classique", textos preparados para palestras radiofônicas de final de 1953 ou início de 1954, inéditos até 1983, quando publicados por Riccardo di Donato pela Maspero, sendo que o segundo nunca foi transmitido, e existia apenas como manuscrito; "La notion de démocratie chez les Grecs", publicado originalmente em 1948 e reeditado em 1983 por R. di Donato; "Le droit pénal public à Athènes", de 1956-1957, reeditado em 1983 pela Maspero.

${ }^{9}$ Um bom estudo sobre o papel da semântica histórica na obra de Gernet, avaliando ao mesmo tempo a presença da preocupação com a língua no grupo de jovens durkheimianos de que ele participava e no próprio Durkheim, assim como mais tarde na História dos Anais e em Vernant, encontra-se em Denis Corrêa (2010). Consiste em um estudo de como Gernet desenvolve, como uma atitude metodológica, a sua "História das Palavras", a qual, segundo ele "demonstra, num estado determinado do pensamento moral, os vínculos que ligam o presente ao passado, a lembrança do estado que precede, e às vezes o pressentimento do estado que segue" (Gernet, 1917, p. 431).

10 "La linguistique était un des éléments de la méthode sociologique de Louis Gernet et sans doute, réciproquement, la sociologie un des éléments de sa méthode linguistique”.

11 "Quant à l'inspiration générale, il est presque superflu de le dire maintenant: nous la devons aux écrits de M. Durkheim et de son école”.
} 


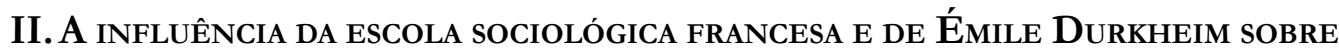 Louis Gernet e sobre a Antropologia da Grécia Antiga}

A Antropologia da Grécia antiga constituiu-se no último terço do século XX em um domínio de estudos da ciência antropológica, sendo ao mesmo tempo um setor de vanguarda dentre os Estudos Clássicos, cuja forte influência em vários países, inclusive o Brasil, se faz sentir com vigor ainda hoje, por exemplo nos estudos de história comparada realizados na Universidade do Rio de Janeiro. A produção científica de autores como Jean-Pierre Vernant, Pierre Vidal-Naquet, Marcel Detienne, Françoise Frontisi-Ducroux e Nicole Loraux, e mesmo representantes estrangeiros da assim chamada Escola de Paris, como o sueco Jesper Svenbro, notabiliza-se como alternativa modelar para a interface entre História e Antropologia. Essas duas disciplinas estão tão visceralmente imbricadas na sua forma de pensar a experiência do homem grego antigo, que não se pode definir facilmente se estão fazendo História ou Antropologia - em verdade, fazem as duas coisas de forma misturada. Neles, encontramos ao mesmo tempo uma antropologia histórica e uma história antropológica.

A identificação dos estudos da Escola de Paris como uma Antropologia da Grécia antiga consagrou-se no final dos anos 60 , em decorrência da publicação de uma coletânea de artigos de Louis Gernet, em 1968, seis anos após sua morte, sob o título de Anthropologie de la Grèce antique. Fazia algum tempo, porém, que nomeava seus trabalhos sob a égide da Antropologia. Já de volta a Paris, lecionava desde 1948 um seminário de Sociologia Jurídica na École des Hautes Études en Sciences Sociales, no qual de fato ensinava uma Antropologia histórica da Grécia antiga. Desde 1949, seus laços com a Antropologia se consolidam institucionalmente na sua função de secretário geral da revista Année Sociologique, cargo em que permanece até 1961, pouco antes de morrer em janeiro de 1962.

Pouco após sua morte, Vernant - um dos responsáveis por essa publicação póstuma - homenageou seu mestre criando em 1964 o centro de estudos helenistas parisiense denominado Centre Louis Gernet, ligado à École Pratique des Hautes Études (EPHE), depois à École des Hautes Études en Sciences Sociales (EHESS). Foi seu primeiro diretor, seguido por Pierre Vidal-Naquet, François Lissarrague e François Hartog. Sob a direção de François Polignac, ocorreu uma reorganização institucional, com a fusão do Centre Louis Gernet ao Centre Gustave Glotz (Mondes hellénistique et romain) e ao Phéacie (Pratiques culturelles dans les sociétés grecque et romaine), criando-se o ANHIMA (Anthropologie et histoire des mondes antiques), dirigido por Violaine Sebillote Cuchet desde 2014.

Gernet é considerado, numa perspectiva da academia francesa, um turning point nos Estudos Clássicos, devido à introdução dos conceitos e noções da antropologia nos estudos da Grécia antiga. Nosso objetivo será, destacando a dimensão antropológica da obra de Gernet, buscar identificar (i) a filiação deste à escola sociológica francesa e (ii) a influência de Émile Durkheim sobre ele.

Desse modo, queremos destacar a importância da Antropologia francesa na renovação dos estudos helênicos, com impacto variado sobre diferentes áreas, como os estudos filológicos, históricos, filosóficos, arqueológicos, iconográficos e numismáticos; ademais, preocupamo-nos em evidenciar como esse entrecruzamento entre História 
e Antropologia não é uma novidade dos anos 60 e da Nouvelle Histoire, como um estudante pouco informado pode pensar, mas advém de intelectuais da primeira geração da historiografia europeia do século XX, mesmo que fossem pensadores dissidentes do pensamento hegemônico nas universidades francesas da época - e que, no caso de Gernet, a dissidência intelectual foi acompanhada pelo ativismo de esquerda, pela militância socialista e marcadamente anticolonialista a partir do final dos anos 30, em especial no que se refere à Argélia.

A renovação antropológica do helenismo proposta por Gernet foi mal acolhida na academia francesa. Na Inglaterra, a contribuição da Antropologia aos Estudos Clássicos foi mais bem recebida já no início do século, como indica a publicação em 1908 de seis palestras proferidas em Oxford, organizada pelo etnologista britânico Robert Ranulph Marett (1866-1943), que em 1910 veio a suceder Edward B. Tylor (1832-1917) como professor de Antropologia em Oxford. A proposta de Marett, por meio da publicação desta coletânea, era estimular a aproximação entre os saberes produzidos pelos estudos antropológicos dos povos primitivos e os estudos das culturas da dita Antiguidade clássica (Grécia e Roma): "Anthropology must cast forwards, the Humanities cast back" - afirmava que, com esse ciclo de conferências, a Antropologia dava o primeiro passo nessa aproximação (Marett, 1908, p. 3). Esta publicação foi intitulada Anthropology and the classics: six lectures delivered before the University of Oxford, com as conferências de Arthur Evans (1851-1941), Andrew Lang (1844-1912), Frank Byron Jevons (1858-1936), John Lintor Myres (1869-1954), William Warde Fowler (1847-1921) e do classicista australiano Gilbert Murray (1866-1957), cuja leitura exerceu importante influência sobre o próprio Gernet. Enquanto Lang dedica-se às relações entre Homero e a Antropologia, Myres propõe a mesma reflexão com relação a Heródoto, ao passo que Jevons estuda a magia greco-italiana e Murray antropologiza o olhar sobre a epopeia grega, sendo ele seguramente um dos pioneiros da abordagem antropológica nos Estudos Clássicos.

Para entendermos o caráter da obra de Gernet, é interessante identificar e localizar o convívio intelectual de sua juventude. Foi colega do sinólogo Marcel Granet (1884-1940) na École Normale, onde ingressou em 1902, e posteriormente na Fundação Thiers, onde foi bolsista entre 1907 e 1914, somando-se ali a Marc Bloch, para compor o que Jacques Le Goff chamou o "trio da Fundação Thiers" (Le Goff, 1993, p. 11). No início do século, participou, junto com o amigo Granet, do clube dos Cabiers $d u$ Socialiste, o qual conectava, em torno de Robert Herz (1881-1915), ${ }^{12}$ a nata da jovem inteligência sociológica: Antoine Bianconi (1882-1915), Maurice Halbwachs (1877-1945), Marcel Mauss (1872-1950), Henri Lévy-Bruhl (1884-1964), François Simiand (1873-1935) e Emmanuel Lévy (1871-1944). O grupo, que tinha uma evidente simpatia pelos fabianos ingleses, manteve-se unido até a

\footnotetext{
12 Aluno e amigo de Marcel Mauss, discípulo de Émile Durkheim, judeu, socialista, faleceu precocemente aos 33 anos em um ataque na Primeira Grande Guerra Mundial, em que serviu na infantaria, interrompendo próspera carreira. Autor seminal, dedicou-se, entre outros temas, às representações coletivas da morte e ao estudo de festas religiosas. Após seu falecimento, seu trabalho foi divulgado por Durkheim, Evans Pritchard e Marcel Mauss.
} 
Primeira Guerra Mundial, que causou sua desagregação com a morte em campo de batalha do próprio Herz, e de outros membros, como Bianconi. Todos atestavam uma profunda influência de Émile Durkheim e tinham no Année Sociologique, revista fundada em 1896 pelo mestre, o lugar referencial de seus debates (Donato, 1983, p. 405-6).

A respeitosa recusa da tradição fusteliana, por parte de Gernet, fundamentava-se nos conceitos sobre o "homem" - sobre sua cultura e sociedade - discutidos e burilados nos diversos artigos publicados no Année Sociologique. O próprio Gernet publicou artigos no Année a partir de 1906. Já entre 1903 e 1906, juntou-se ao economista François Simiand na redação das Notes critiques - Sciences Sociales, fundada por este em 1900, que publicava resenhas, indicações bibliográficas e sumários de revistas, mostrando o engajamento com a divulgação dos estudos sociológicos.

Em sua tese de doutorado, Recherches sur le développement de la pensée juridique et morale en Grèce. Étude Sémantique, Gernet menciona a contribuição de "vários trabalhos da escola sociológica" (Gernet, 1917, p. XVI, nota 12). Ao expor seus pressupostos teóricos, afirma que deve a inspiração geral aos escritos de Émile Durkheim e sua escola (Gernet, 1917, p. XVIII). A influência de seu mestre na sociologia já pode ser atestada na primeira página do préfacio, na segunda nota, quando Gernet cita Les formes élementaires de la vie religieuse (1912). Ao longo da obra, encontramos referências a vários artigos, de diferentes autores, publicados no Année Sociologique. Podemos aqui citar alguns deles:

CROISET, M. Démocraties Antiques. Review by: GERNET, L. L'Année Sociologique, v. 11, p. 331-335, 1906.

DURKHEIM, É. Définitions des phénomènes religieuses. L'Année Sociologique, v. 2, p. 1-28, 1897-1898.

DURKHEIM, É.; MAUSS, M. De quelques formes primitives de classification. L'Année Sociologique, v. 6, p. 1-72, 1903.

HERZ, R. Contribution à une étude sur la répresentation collective de la mort. L'Année Sociologique, v. 10, p. 48-137, 1907.

HUBERT, H.; MAUSS, M. Théorie générale de la magie. L'Année Sociologique, v. 7, p. 1-146, 1904.

HUVELIN, P. Magie et droit individuel. L'Année Sociologique, v. 10, p. 1-47, 1907.

MAUSS, M. Les tribus de l'Australie du Sud-Est. L'Année Sociologique, v. 9, p. 177-183, 1906.

MEILLET, A. Comment les mots changent de sens. L'Année Sociologique, v. 9, p. 1-38, 1906.

Gernet cita também obras de outros importantes autores da nascente ciência antropológica. Assim, além da evidente filiação a Durkheim e Mauss, ${ }^{13}$ a leitura de James G. Frazer (1854-1941), de Lucien Lévy-Bruhl (1857-1939) e sobretudo do australiano e igualmente helenista Gilbert Murray, foi importante para Gernet dar contornos

\footnotetext{
${ }^{13}$ A influência de Mauss se fez sentir de forma mais forte sobre o sinólogo Marcel Granet, amigo e colega de Gernet.
} 
antropológicos à concepção de homem primitivo, a fim de poder estudar a passagem, no pensamento jurídico, de um pensamento mágico, mítico e concreto, a um pensamento positivo, racional e abstrato. Em Frazer, por exemplo, Gernet buscou uma definição de mana para auxiliar, inspirado em Murray, o entendimento do conteúdo mágico envolvido no poder em Homero. Assim, Gernet cita as seguintes obras:

FRAZER, J. G. Lectures in the Early History of the Kingship. London: Macmillan, 1905. LÉVY-BRUHL, L. Les fonctions mentales dans les sociétés inferieures. Paris: P. U. F., 1910.

MURRAY, G. The early Greek epic. In: EVANS, A. et al. Anthropology and the Classics. Oxford: Clarendon Press, 1908.

Alguns artigos e obras, sobre temas de interesse antropológico, são citados por Gernet. Podemos lembrar alguns deles:

HUBERT, H.; MAUSS, M. Mélanges d'histoire des religions. Paris: F. Alcan, 1909.

HUVELIN, P. Les tablettes magiques et le droit romain. Annales internationales d'bistoire. Mémoire présenté au Congrès International d'Histoire Comparée, Paris, 1900.

Marett, na Grã-Bretanha, dizia que a Antropologia dera o primeiro passo no sentido de aproximação, incitando os classicistas à reciprocidade. Do outro lado do Canal da Mancha, Gernet respondeu ao chamado, e é isso que fez em sua tese de doutorado: deu um passo enorme no sentido de aproximar os Estudos Clássicos da Antropologia. Essa aproximação foi amplamente rejeitada na França, mas ele não estava sozinho nesse movimento. Sua pesquisa sobre o pensamento jurídico não teria sido possível se, antes dele, Gustave Glotz não tivesse se dedicado a um estudo minucioso das permanências do direito familiar, gentílico, na pólis institucionalmente organizada. A obra de Glotz La solidarité de la familie dans le droit criminel en Grèce (1904) está na base de todo o estudo de Gernet sobre o desenvolvimento do pensamento jurídico e moral na Grécia antiga.

A dimensão filológica de sua pesquisa foi igualmente influenciada pela escola sociológica francesa. Apesar da grande admiração que tinha na juventude pelos prussianos e pela monumental escola filológica a Leste do Reno, recusou-se a seguir os passos do positivismo alemão, que tinha em Willamowitz (1848-1931) o seu mentor, e optou pela linguística de Antoine Meillet (1866-1936), cujos escritos circunscreviam o fenômeno da língua no domínio do social. Dois textos de Meillet foram de suma importância para a formação do Gernet filólogo: "Comment les mots changent de sens", publicado no Année Sociologique (IX, 1906), e "L'état actuel des études de linguistique générale. Léçon d'ouverture du cours de grammaire comparée au Collège de France", publicado na Révue des Idées (1906).

Em nossa análise, procuraremos demonstrar a influência, sobre Louis Gernet, de Émile Durkheim e da escola sociológica francesa - e, de modo mais difuso, da antropologia europeia da virada de século - em quatro aspectos fundamentais que balizam a obra Recherches sur le développement de la pensée juridique et morale en Grèce antique. Étude Sémantique, os quais analisaremos logo a seguir. Concentramo-nos mais nesta obra, em parte para homenagear seu recente centenário, mas também porque queremos focar na genealogia de suas ideias 
e procedimentos, evidenciando-os na produção da juventude. A partir da década de 20 , Gernet se libertará um pouco da rigidez do edifício teórico de Durkheim, na medida em que estreitava sua ligação à psicologia histórica de Ignace Meyerson (1888-1983) e explorava com mais liberdade as possibilidades que sua abordagem da semântica histórica propiciava em termos de uma história das mentalidades avant la lettre - mas isto é tema para outro estudo, o que Denis Corrêa (2010) analisou como a "história das palavras" de Gernet.

\section{A IDEIA DE QUE O PENSAMENTo Não SE EXPLICITA}

Segundo Gernet, um dos problemas metodológicos mais graves para se estudar o pensamento jurídico e moral é o fato de que o pensamento não se explicita, pois a vida diária, pela sua própria vulgaridade, é composta por um grande número de relações que permanecem desapercebidas, que muitas vezes não saem de um plano inconsciente (Gernet, 1917, p. 71). A preocupação de Gernet respeita a necessidade de se alcançar o nível deste inconsciente. Ora, conforme Claude Lévi-Strauss, é aí que se encontra a diferença precípua entre o método da História e da Etnologia: enquanto "a história [organiza] seus dados em relação às expressões conscientes, a etnologia [o faz] em relação às condições inconscientes da vida social" (Lévi-Strauss, 1985, p. 34). Bem, o interesse que move as Recherches são precisamente essas condições inconscientes da vida social.

Nesse aspecto, o interesse intelectual de Gernet está comprometido com as premissas que a Antropologia vinha sustentando desde o final do século XIX, e que a escola sociólogica francesa - da qual Gernet foi um partícipe - tratou de aperfeiçoar. Já E. Tylor, que estudara a cultura - num sentido de "civilização" - como um conjunto complexo em que se ordenam conhecimentos, crenças, arte, moral, direito e costumes do homem, asseveraria que a marca da etnologia estava em saber que esses fenômenos não eram passíveis de explicação por meio das formas conscientes. Ou seja, esses fenômenos não se explicitam.

A etnologia deve, portanto, conforme formalizará mais tarde Lévi-Strauss, atingir a estrutura do inconsciente, subjacente a cada instituição ou cada costume. Desse modo, Gernet, na mesma direção, fazia uma espécie de "etnologia histórica" (se é que podemos usar esse termo), ao buscar, através de um estudo semântico, as estruturas inconscientes que regem o desenvolvimento do pensamento jurídico e moral e a organização das instituições judiciais.

\section{A SEmântica e as mentalidades}

O estudo semântico é o caminho de acesso às categorias mentais, que em última instância organizam a percepção do mundo e da sociedade, percepção manifesta tanto nas representações coletivas quanto nas individuais.

Mauss, sobretudo, mas também Durkheim, assentaram solidamente um dos alicerces do método da ciência antropológica: trabalhar com as categorias nativas tornouse uma obrigação universal do antropólogo. Gernet, participando dos debates intelectuais do grupo que se reunia em torno do Année Sociologique, sob influência de Émile Durkheim, 
parece ter aprendido bem esse pressuposto. Para ele, a filologia - reformulada - serviu de instrumento para a antropologização da história, na medida em que, através da história dos sentidos atribuídos ao vocábulo jurídico, conseguiu recuperar as "categorias nativas" gregas de representação coletiva do mundo e da sociedade.

Gernet empreendeu um estudo semântico, sob a influência teórica de Meillet, em que as variações dos sentidos das palavras apareciam como uma relação ativa e dinâmica entre língua e sociedade. Em sua filologia deveras filológica (Gernet, 1917, p. X), a palavra tornava-se, assim, um documento para o historiador, guardando em si não só sentido mas também valor, simbolizando a unidade da consciência coletiva (Gernet, 1917, p. XI-XII). Para Gernet, atrás de cada termo há um pensamento escondido, fundamento de uma realidade psicológica. Ele escolhe a língua como fonte histórica, porque ela traduz pensamentos e sentimentos, comuns ao grupo, que estão presentes tanto no plano institucional como no plano mental (Gernet, 1917, p. VIII). É a língua, portanto, que dá acesso às "condições inconscientes" referidas por Lévi-Strauss, aquelas que "não se explicitam", mas sustentam a estruturação tanto das instituições como do pensamento. Ela é, concretamente, o veículo de contato com as "representações coletivas".

\section{A PERMANÊNCIA Do "ANTIGO" NO "NOVO"}

Trata-se da permanência de representações antigas (da ordem da religião e da família), exercendo um papel fundamental na estruturação do "novo" (que se apresenta como sendo da ordem da razão e da cidade).

Através do estudo histórico do percurso do sentido das palavras referentes ao universo jurídico e moral, Gernet averigua a continuidade de sentimentos oriundos da religiosidade e dos laços familiares homéricos. Desse modo, ele evidencia como a ordem antiga, social e religiosa, fornece as estruturas ${ }^{14}$ elementares para a organização da nova ordem. A permanência do "antigo" se ramifica, na abordagem de Gernet, em dois aspectos preponderantes: primeiro, a permanência de ideias religiosas, da ordem do mito, na sociedade que se reorganiza com base na emergência da razão (do lógos), e, segundo, a resiliência da familia (esfera privada) na pólis (esfera pública).

\section{A permanênCia de ideias religiosas}

Mantendo-se como um conjunto organizado de representações mentais, a permanência das ideias religiosas é responsável pela interpretação que a sociedade tem do mundo, influindo sobremaneira no desenvolvimento do pensamento e das instituições jurídicas, uma vez que continua a guiar a moral.

O significado que Gernet confere ao fenômeno religioso em seu modelo analítico demonstra sua pertença ao círculo intelectual que gravitava em torno de Émile Durkheim;

\footnotetext{
${ }^{14} \mathrm{O}$ autor não utiliza esse conceito, o que seria em certa medida até anacrônico, mesmo que nós possamos identificar sua presença em sua teoria social.
} 
mais que isso, revela a sua dívida teórica com Les formes élémentaires de la vie religieuse (1912), publicada enquanto desenvolvia seus estudos de doutorado. Aprendendo com Durkheim que através da religião se pode entender o universo cultural dos povos - posto que o fenômeno religioso constituiria, de forma universal, um sistema de representação do mundo - Gernet elegeu o entendimento dos sentimentos religiosos remanescentes na ordem racional da pólis como o procedimento metodológico correto para se alcançar uma compreensão antropológica da cidade grega, com o intuito de abandonar os idealismos e os a priori da imagem romântica do "milagre grego". Superando o preconceito que identificava no pensamento mágicomítico a vigência de um regime de crendices e superstições incompatíveis com o domínio da razão trilhado pela suposta evolução da humanidade, Gernet - divorciando-se, apoiado em Durkheim, dessa visão racionalista eurocêntrica predominante no século XIX - tratou a permanência de sentimentos religiosos como componentes necessários de um conjunto de representações que devem ser analisadas, pois compõem o horizonte por meio do qual o grego interpreta mundo e sociedade.

Desse modo, como parte do processo de organização institucional da pólis, a cidade cria noções racionais e abstratas sobre si mesma - começa a formar-se um imaginário racional da pólis! Mas será sempre um imaginário híbrido, no qual perduram noções religiosas. Muito embora a tendência intelectual fosse o desenvolvimento do lógos, que incidirá sobre o desenvolvimento de diferentes campos do pensamento e da sociedade, como o Direito, a justiça e a política, o sentido de unidade do grupo, no plano do pensamento moral, na psicologia coletiva, seguirá tendo como sustentáculo um conjunto de sentimentos religiosos. São sentimentos que se manifestam de forma dispersa, em esferas variadas, seja na própria política, no Direito, na tragédia, na História como discurso do lógos sobre o passado, mas até mesmo em concepções de espaço. $\mathrm{O}$ fundamento da unidade coletiva, da solidariedade social, ainda será o pensamento mágico-religioso, o qual tem sobrevida dentro do Direito instituído da pólis: para Gernet, a noção de justiça, moral no seu conteúdo, jurídica na reação coletiva que provoca, é ainda fundamentalmente religiosa nos seus princípios.

A percepção de adikía (injustiça) seguirá sendo motivada por sentimentos religiosos, que alimentam a ideia de que uma ordem substancial do mundo é atingida quando ocorre uma transgressão. Essa transgressão, propriamente o que gera a injustiça, é percebida magicamente como uma eficácia sinistra de forças religiosas indefinidas. Na noção de adikía está presente uma noção religosa do kósmos, bem como do tempo. O adíkema (delito), a ação injusta, é sentida pela coletividade, de modo difuso, como uma força religiosa, uma força contagiante, uma doença espiritual, que pode contaminar a sociedade. Por esse motivo é necessário que não haja contato físico ou contiguidade espacial com o ádikos (o criminoso), uma vez que sua impureza contagia. Acreditava-se que a proximidade ou contato com o criminoso poderia trazer a fúria divina e suas drásticas consequências punitivas. Os deuses poderiam não distinguir quem é puro ou impuro, quem realmente cometeu atentado ao sacro e quem foi apenas vítima do contágio pelos signos do impuro, pois os miasmas gerados pelo adíkema podem trazer energia negativa que recai sobre toda a sociedade. Assim, um assassino não pode ser enterrado na mesma necrópole usada pelo restante dos indivíduos, mas em local apartado, pois há miasmas negativos que o acompanham. 
É comum que um delito público seja sentido e judicializado como atentado à ordem sagrada e, inversamente, que se conceba o delito religioso como uma agressão à ordem pública - daí a asébeia ser julgada na Assembleia, e não na Helieia ou no Areópago. Público e religioso, distinguidos no plano do consciente, confundem-se no nível do inconsciente. Exemplo disso é o saque às riquezas da cidade ou ainda a traição na política ou na guerra: são delitos públicos, mas tratados como violação à ordem sagrada. Qualquer forma de desrespeito aos frutos sagrados das oliveiras de Atenas (pertencentes à deusa Atena), é, por sua vez, um crime religioso, uma profanação, que agride a ordem pública. É um pensamento mítico-místico que continuará a dar as bases da solidariedade social. Podemos citar quatro exemplos abordados por Gernet da persistência de noções religiosas:

- O desrespeito à Constituição e às leis, por exemplo, era tomado como sacrilégio. Considerava-se um ato sacrílego a supressão de uma lei, porque ela era resultado de uma convenção humana (o nómos) que, apesar de conscientemente entendida como resultado de deliberação humana, seguia envolvida por significados religiosos. Exemplo disso: em Atenas, as leis eram guardadas no Métroon, santuário dedicado à Reia, Mãe dos Deuses, que funcionava junto à estrutura do antigo Bouleuterion, construído à época de Clístenes. Em espaço que seria integrado a este prédio, podem ser identificadas as fundações do pequeno templo arcaico da Mãe dos Deuses, provavelmente destruído pelos persas em 480/479 a.C., localizadas abaixo da sala mais setentrional do Métroon helenístico do séc. II a.C., de estruturas mais bem conservadas. No final do século V, foi construído um novo Bouleuterion, a oeste do antigo, para onde se transferiram as reuniões dos conselheiros. $\mathrm{O}$ antigo Bouleuterion assim passa a dar conta de acomodar um volume bem maior de documentos públicos, em papiro, pergaminho ou tabuinhas com fundo branco, como exigia a democracia mais complexa da época. Os arquivos e o culto a Reia continuam assim a partilhar o mesmo prédio. Essa fusão entre função arquivística e ritualística por si só conferia às leis um caráter sagrado inerente. Ao mesmo tempo, a conservação dos arquivos públicos em um santuário contribuía para reforçar a confiança em sua autenticidade (Camp II, 1990, p. 62-66; Gagnon-Arguin, 1998, p. 33).

- O suicídio era visto como um delito de natureza religiosa e efeito político: era um crime contra a cidade, interpretado por elementos místicos. Para anular o efeito sinistro do phántasma, da força sobrenatural que levara o suicida a ofender a cidade, sua mão deveria ser enterrada em separado do corpo, pois se acreditava que ela poderia continuar exercendo efeitos nefandos sobre a cidade, uma vez que fora na mão que se alojara a eficácia malévola do phántasma que provocara a agressão.

- A substância do sentido religioso da cidade está imbricada na relação que amarra o grupo político-social e o solo sobre o qual a comunidade se assenta. Grupo e solo comunicam-se ao serem impregnados de uma virtude religiosa. Desse 
modo, um delito público que seja um atentado às regras referentes às coisas do solo acarreta igualmente um delito religioso.

- O modo como a cidade encara o estrangeiro também está impregnado de sentido religioso, pelos mesmos motivos místicos que ligam a comunidade ao seu solo, uma vez que solo, comunidade, antepassados, espíritos dos mortos, deuses pátrios e deuses do lar compõem um todo coeso, que a aplicação do modelo de Durkheim permite explicar pela relação entre as estruturas clânicas e o totemismo. Ele identificou nos relatos etnográficos uma estreita relação entre o grupo humano e a unidade clânica. Neste esquema mental, o estrangeiro é sempre estranho a essa unidade clânico-totêmica.

Destarte, há uma correspondência, em muitos casos, entra a noção de atentado ao sagrado da pólis e a ideia geral de delito público, associando-se sempre o pensamento mítico-místico ao racional. Isto porque o bem da cidade é da ordem do sagrado, visto que este é definidor do que seja o bem público, o qual não é independente da boa vontade dos deuses, que esperam dos homens o respeito às coisas sagradas. Mesmo com a laicização do conceito de delito, ainda será uma noção híbrida, que mistura o político e o religioso, que fundamentará o direito público. Exemplo disso, a noção de asébeia (impiedade), essencialmente religiosa na sua origem, passa a ser concebida como um delito público contra a ordem civil. No entanto, essa noção é uma complexa orquestração entre o "novo" e o "velho".

A instalação de um processo de impiedade, na Atenas democrática, responde às necessidades da pólis instituída, no âmbito de relações políticas e sociais como a educação dos jovens e o ensino filosófico. Mas a sua solução, o seu julgamento, é movido por regras advindas do passado religioso. Assim compreendemos o sentido da acusação tanto de Sócrates como de Protágoras. Eles foram submetidos a um processo de acusação por impiedade (asébeia), por terem incitado o não-conformismo nas suas práticas de ensino, por entenderem que eles estimulavam entre os jovens formas de descrédito na ordem divina. No plano do inconsciente, o conceito de asébeia traduz uma ortodoxia moral indissoluvelmente política e religiosa, que permeia a percepção inconsciente de uma ordem das coisas, de uma ordem de fundo religioso, mágico (Gernet; Boulanger, 1970, p. 286-93).

No âmago da sociedade organizada e racional que constitui a pólis, o místico e o sobrenatural dão forma ao sentimento vivo de solidariedade como um pensamento religioso. O conteúdo religioso do pensamento jurídico une o indivíduo à cidade, o privado ao público.

Desse modo, por detrás da aparente dicotomia entre o religioso e o humano, entre o mítico e o racional, Gernet chega em algo da unicidade essencial da pólis, no plano da mentalidade: o grego não teria uma percepção destas "duplas de opostos" como antinomias irredutíveis. Não via entre elas uma polarização, já que humano e religioso, profano e sagrado, mŷthos e lógos, fundavam-se e garantiam-se mutuamente. A ideia de uma coletividade social como princípio de soberania tinha como fundamento a comunidade concreta sentida como entidade religiosa (Gernet, 1983c, p. 274). 
O tratamento que Gernet confere à influência dos fenômenos mentais de ordem religiosa sobre a estruturação do pensamento jurídico e moral revela sua atenção a problemas teóricos centrais na obra de Durkheim. Assim, três questões durkheimianas balizam o seu modelo analítico e atravessam sua escrita de início a fim: (i) as relações entre o sagrado e o profano, (ii) entre o natural e o sobrenatural, e (iii) entre o mágico-mítico|concreto, e o racional $\mid$ abstrato. ${ }^{15}$

\section{ResiliênCIA dA FAMÍlia (PRIVAdo) NA PÓlis (PÚBliCo)}

A entidade família, integrando-se à cidade, fornece-lhe as convicções passionais necessárias ao desenvolvimento moral do sentido de justiça. A questão durkheimiana das estruturas clânicas é tratada por Gernet sob a ótica das representações atinentes ao universo familial. Essas representações condensam a memória de valores oriundos do universo aristocrático do génos homérico, da unidade sócio-econômica do ô̂kos. Um dos pressupostos básicos da pesquisa de Gernet é que a permanência dos sentimentos familiares de origem gentílica constitui o núcleo da solidariedade social na pólis. Essa premissa foi solidamente estabelecida e demonstrada por Gustave Glotz, em sua obra La solidarité de la famille dans le droit criminel en Grèce, publicada em 1904, cuja leitura exerceu influência determinante na interpretação que Gernet formulou acerca da questão jurídica na cidade grega.

Assim, nada obstante a ascensão do indivíduo na esfera do Direito, que acompanhou o abandono do grupo familial como átomo social - passando o indivíduo a ocupar esse papel na regulamentação das relações sociais (ao menos políticas e jurídicas) -, a família, com seus sentimentos aristocráticos, teria resistido em conteúdo e espécie. A cidade, em seu direito criminal, viu-se insuflada por sentimentos e por uma mentalidade outrora vigentes no interior da ordem familial-aristocrática (a ordem do génos). Ao proteger o indivíduo, a cidade o protege, no plano privado, enquanto emanação da família. Defendendo o público, defende também o ôkkos, veia pela qual o "antigo" incessantemente penetra o "novo", pela qual o génos persistentemente se assimila à cidade. Gernet acredita assim que é o próprio universo de valores aristocráticos tradicionais que amarra e assegura a solidariedade na pólis. Nela, o direito público, expressão e garantia de seu stablishment, funda-se na persistência dos elementos familiares (privados), fenômeno muito bem exemplificado nos procedimentos jurídicos, como o demonstra Gernet no seguinte trecho:

O homicídio foi definido como delito quando, concluída a integração das famílias na cidade, o sentimento dos parentes foi compartilhado pelos outros cidadãos, quando esses passaram a designar o assassino pela palavra authéntes, a mesma que era anteriormente empregada pelos parentes. E justamente a evolução desses dois termos, $\alpha \mathfrak{v} \theta \dot{v} v \tau \eta \varsigma \mathrm{e}$

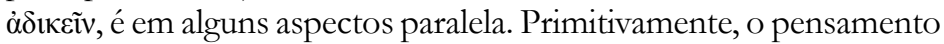
situa-se no quadro da família, authéntes significando aquele que mata

\footnotetext{
${ }^{15}$ Nesse terceiro item, Gernet trata de uma questão muito cara a Durkheim: a relação entre a religião e a ciência como sistemas de interpretação do mundo.
} 
um de seus parentes, depois significa o assassino estrangeiro, cujo ato, apreciado pelos parentes, requer da parte desses e em favor da vítima

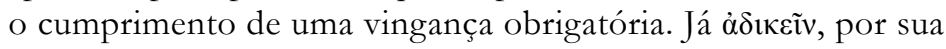
vez, designa a ofensa ao morto, especialmente aquela que resulta de quando não se permite que se vingue um parente. Agora - na cidade definitivamente constituída - é a mesma necessidade de reparação, o mesmo sentimento religioso que se manifesta em tudo. A evolução dos termos reflete o progresso das instituições: a prorrhesis [sentença condenatória] emanava primitivamente do parente mais próximo, finalmente é o arconte-rei que, em nome da cidade, a pronuncia (Gernet, 1917, p. 78). ${ }^{16}$

Percebe-se, então, um processo psicológico inconsciente de uma continuidade interna à mudança: a solidariedade social da pólis é alinhavada pela integração a si do pano de fundo familial-aristocrático, como Gernet coloca, na seguinte passagem:

Se a sociedade protege seus membros contra as ofensas que lhes podem atingir, não o faz, em princípio, para eles mesmos, nem em virtude de uma simpatia espontânea: a cidade não integra a si os indivíduos, mas os grupos. É por isso que a família, na repressão do assassinato, continua a ter a iniciativa e o privilégio da perseguição; é também porque tudo o que representa na vida do direito o prolongamento do passado e a persistência das relações familiares atesta e confirma o mesmo processo psicológico (Gernet, 1917, p. 79, grifos do texto original). ${ }^{17}$

16 'L'homicide a été défini délit lorsque, l'intégration des familles dans la cité se trouvant achevée, le sentiment éprouvé par les parents fut partagé par les autres citoyens, lorsque ceux-ci désignèrent le

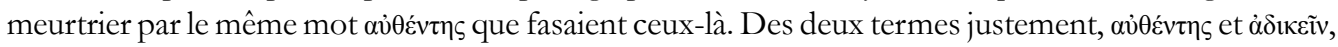
l'évolution est à certains égards parallèle. Primitivement, la pensée se situe dans le cadre de la famille,

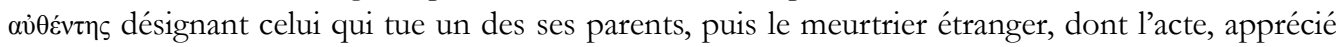
par les parents, appelle de leur part et en faveur de la victime l'accomplissement d'une vengeance

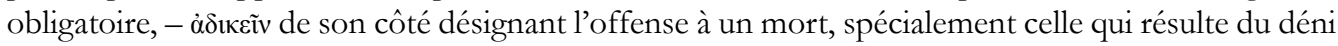
de vengeance d'un parent. Maintenant - dans la cité définitivement constituée - c'est le même besoin de réparation, le même sentiment religieux qui chez tous se manifeste. L'évolution des termes reflète

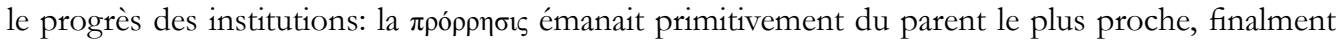
c'est l'archonte-roi qui, au nom de la cité, la prononce."

17 “[...] si la société protège ses membres contre les offenses qui les peuvent atteindre, ce n'est pas pour eux-mêmes dans le principe, ni en vertu d'une sympathie spontanée: la société ne s'intégre pas les individus, elle intègre des groupes. C'est bien pourquoi la famille, dans la répression du meurtre, continue d'avoir l'initiative et le privilège de la poursuite; c'est aussi pourquoi tout ce qui représente dans la vie du droit le prolongement du passé, la persistence des rapports familiaux, atteste et confirme le même procès psychologique." 
O principal exemplo dos sentimentos aristocráticos é a sobrevida das distantes convicções passionais da família processadas no direito através da noção de vingança. A justiça organizada da pólis alimenta-se todo o tempo de um sentimento difuso de vingança coletiva, continuidade daquilo que havia de essencial na noção de penalidade bruta, própria à moral gentílica. $\mathrm{E}$ a vingança tem sempre, em última instância, um vínculo com o sangue: $\mathrm{e}$ a cidade-Estado respeita os laços sanguíneos, mesmo que estes se oponham potencialmente ao domínio do público, do comum, do impessoal, que deveriam caracterizar a experiência coletiva da pólis.

Desse modo, o que Gernet destacou é que, na pólis, a racionalização intelectual, a democratização política e a individuação jurídica e institucional não implicaram a extinção de traços tradicionais - aristocráticos, familiais e gentílicos - pois esses constituíram sempre um pano de fundo de reminiscências comuns, um caldo de cultura, que instrumentalizou o processo de institucionalização e organização da cidade. Esses aspectos tradicionais foram propriamente elementos ativos, mesmo que enquanto uma espécie de gene recessivo muito poderoso, já que a família foi sempre concebida, aponta Gernet, como uma unidade, um ideal ao qual o indivíduo deve sacrificar seu egoísmo.

Assim, os padrões coletivos, a atitude exemplar, têm seus fundamentos na antiga solidariedade familial-gentílica, aristocrática. Eis por que a principal prerrogativa do cidadão é a sua honra (timé), sentimento profundamente arraigado num espírito nobiliárquico:

Há no cidadão uma qualidade de orgulho humano que o torna comparável ao nobre; reconhecê-la-íamos até em certas opiniões duráveis como o desdém pelo comércio. E a noção de nobreza prolonga-se, na literatura e na filosofia, tanto pela concepção dos "melhores", distinguidos por seu gênero de vida e comportamento, quanto, até, pela especulação sobre a "natureza" moral que é também o "nascimento" [...]. O tipo de virtude que aparece na ética descritiva de Aristóteles detém muito de um ideal antigo, no seio mesmo da cidade igualitária. Na formação do grego da idade clássica, a herança de um passado nobre foi certamente fundamental (Gernet, 1982a, p. 228). ${ }^{18}$

Dessa forma, Gernet buscou demonstrar como foi a universalização das crenças familiais renovadas que fez o indivíduo recuperar no grupo da cidade, na comunidade políade, a confiança que ele experimentava no seio do grupo familiar. Isso ocorreu, porém, de forma inconsciente, abstrata, e pode ser testemunhado pelo historiador ou pelo filólogo por meio do estudo da história do vocabulário jurídico e moral.

18 "Il y a chez le citoyen une qualité d'orgueil humain qui peut le faire comparer au noble; on la reconnaitrait jusque dans certains partis pris durables comme le mépris du mercantile. Et la notion de noblesse se prolonge, dans la littérature et la philosophie, par la conception des 'meilleurs' que distinguent leur genre de vie et leur comportement, voire même par la spéculation sur une 'nature' morale qui est aussi la 'naissance' (...) Le type de vertu qui apparaît dans l'éthique descriptive d'Aristote retient beaucoup d'un idéal ancien, au sein même de la cité égalitaire. Dans la formation du Grec de l'âge classique, l'héritage d'un passé noble a certainement été de conséquence". 


\section{LÓGICA BINÁRIA: COMPLEMENTARIDADE E OPOSIÇÃo ENTRE PARES DE OPOSTOS}

$\mathrm{Na}$ perspectiva inaugurada por Gernet, a complexidade de compreensão da cultura e sociedade gregas exige entender a relação dialética de complementaridade e oposição entre diferentes níveis opostos: de um lado, o pensamento mágico $\mid$ mítico $\mid$ religioso $\mid$ concreto oposto ao pensamento racional $\mid$ positivo $\mid$ dessacralizado $\mid$ abstrato; de outro, o domínio da família (do oîkos) oposto ao da cidade (da pólis).

A contribuição mais importante da obra de Gernet encontra-se no seu modelo de "homem grego". Conforme esse modelo, o homem vive, ao mesmo tempo, numa tensão e complementaridade entre padrões culturais opostos. Mentalmente, temos, por um lado, a magia, o mito e a religião; por outro, a razão, os conceitos abstratos universalizantes. Socialmente, temos, de uma parte, a família; de outra, a cidade - e essas oposições sociais se desdobram num conflito entre as representações referentes, umas, ao universo familiar, e, outras, ao mundo da pólis. O grande defeito da maior parte dos modelos interpretativos da cultura grega estava, à época em que Gernet defendeu seu doutorado em 1917 e ainda por algumas décadas, em não conseguir contemplar, numa mesma interpretação, a dimensão da religião e a da razão, do sagrado e do dessacralizado, do pensamento concreto e do abstrato. Eram reféns de um paradigma evolucionista que pressupunha um caminho linear de superação do mito pela razão, premissa básica dos adeptos da miragem do "milagre grego".

Gernet oferece-nos um modelo durkheimiano para, conceitualmente, entendermos como se arranjam essas oposições: elas traduzem, essencialmente, um jogo entre as formas inconscientes e as formas conscientes. Assim, para ele, a cultura grega queria sempre apresentar uma silhueta racional; porém, escondia sob os contornos de suas manifestações conscientes, implícitos nas formas culturais inconscientes, elementos de uma religiosidade primeva - elementos mágicos, míticos, sacros: "E a religiosidade estará aí somente de forma implícita, até mesmo inconsciente: se ela [a religiosidade] compõe a substância da noção [de delito], ela porém não mais desenhará seus contornos" (Gernet, 1917, p. 42). ${ }^{19}$

Para Gernet, a cidade grega antiga foi uma criação, uma invenção humana, bastante original: uma originalidade firmada sobre a certeza que o grego nutria da pólis como um espaço conceitualmente definido como humano, espaço de compromissos cidadãos, regido pela deliberação de iguais reunidos em assembleia, organizado conforme instituições impessoais, dessacralizadas. Era essa a particularidade da cidade grega: "A marca característica da cidade grega é, se assim posso dizer, não atribuir nenhuma substância religiosa nem à organização do Estado nem aos detentores da autoridade" (Gernet 1983a, p. 59-60). ${ }^{20}$

No entanto, como vimos, a percepção que a comunidade tinha de si mesma estava imbuída de um conteúdo religioso - próprio de uma "forma elementar da vida religiosa":

\footnotetext{
19 "Et le religieux n'y sera plus qu'implicite, sinon même inconscient: s'il fait la substance de la notion, il n'en dessinera plus les contours". Aqui Gernet se refere à noção de delito presente nas palavras $\dot{\alpha} \delta$

20 "Mais la marque de la cité grecque, c'est de n'attribuer, si je puis dire, aucune substance religieuse ni à l'organisation de l'État ni aux détenteurs de l'autorité".
} 
[A] comunidade do sagrado [que constituía a cidade] que é uma realidade ao mesmo tempo tão una e tão complexa, envolvendo seres e coisas e se estendendo à terra que alimenta aos vivos, recebe os mortos, é indissoluvelmente associada, pela religião, ao próprio grupo (Gernet, 1917, p. 116). ${ }^{21}$

Desse modo, a perspectiva antropológica que funda a interpretação de Gernet levou a redimensionar, inclusive, a definição da originalidade da pólis grega. Não é mais aquela do mito do "milagre grego", que só tinha olhos para a razão e para a idealização da democracia como indicadores de evolução. Não é mais a ilusória originalidade da suposta ruptura entre o lógos e o mŷthos. A pólis e a cultura políade foram originais, de acordo com Gernet, no modo como assimilaram a si as formas passadas como um garante de seu funcionamento presente, conforme as regras do [formal e aparentemente] "novo". A cidade clássica guarda em si o inconsciente de uma tradição ao mesmo tempo prolongada e renovada pela evolução da sociedade. Ele destacou a necessidade inelutável de se entender, antes de tudo, como o conteúdo de uma solidariedade social passada (clânica) pôde ensejar que uma nova solidariedade (a solidariedade políade) fosse tecida. Ora, a solidariedade social da cidade foi concebida sob a inspiração dos sentimentos familiais, clânicos, aristocráticos, como atesta a sobrevida de sentimentos tradicionais no Direito - apesar de as formas conscientes apresentarem sempre o predomínio do público, do comum, do impessoal. O "novo" recorreu ao conteúdo do "velho" para poder estabelecer-se, tendo nele encontrado o sentido de coletividade para resolver o problema da anomía, da stásis, drama sócio-econômico e cultural dos séculos VIII e VII a.C. Destarte, há uma heterogeneidade cultural interna, constitutiva da unidade da pólis - heterogeneidade que não pode ser esquecida pelo historiador, e que só pode ser percebida no horizonte de uma Antropologia histórica, quando se busca compreender as "categorias culturais do nativo", o que Gernet entende ser viável a partir do estudo de uma semântica histórica.

\section{Considerações FINAIS}

Procuramos evidenciar, ao longo desse estudo, através da análise da interpretação de Gernet de alguns aspectos da cidade e da cultura gregas, a influência exercida sobre ele por Émile Durkheim, em específico, e pela escola sociólogica francesa, em geral. Ao mesmo tempo, tributamos a essa influência o papel de Gernet na formação de uma Antropologia histórica no campo dos Estudos Clássicos, determinante para os novos rumos que os estudos da Grécia antiga tomaram a partir da constituição da Escola de Paris, em meados da década de 1960. Basicamente, podemos apontar oito aspectos da obra de Gernet que testemunham a influência da antropologia francesa do início do século:

\footnotetext{
21 “[...] cette communauté du sacré qui est une réalité à la fois si une et si complexe, embrassant les êtres et les choses et s'étendant à la terre qui nourrit les vivants, reçoit les morts, est indissolublement associée par la religion au groupe lui-même”.
} 
- A religião vista como sistema de interpretação de mundo.

- A percepção do papel da magia e do pensamento concreto nas formas primitivas de religiosidade.

- O papel dessas formas na manutenção do sentimento de solidariedade social, presente na noção vigente de comunidade, em que se imagina uma ligação estreita, coesa, entre os vivos, o solo onde vivem, os antepassados desses vivos enterrados nesse solo, os espíritos desses e os deuses.

- A conexão entre o Direito e a religião, estando o pensamento jurídico sobredeterminado pelas categorias mentais e morais postas pela religião, não obstante o processo de humanização, individuação e racionalização do Direito no âmbito da institucionalização jurídica da pólis.

- A língua vista como fato social e, portanto, como documento que enseja ao historiador e ao filólogo, na perspectiva de uma Antropologia histórica, o acesso às categorias nativas dos gregos antigos.

- A relação entre as formas conscientes e as formas inconscientes, as primeiras dando os contornos da cultura grega políade, enquanto as últimas fornecem a sua substância.

- A questão durkheimiana da relação entre ciência e religião é colocada ao mesmo tempo em que Gernet reflete sobre as relações entre o "novo" e o "antigo", entre o consciente e o inconsciente.

- A permanência do "antigo" (elementar, religioso, mítico, mágico) no "novo" (racional, dessacralizado, abstrato), funcionando como fator estabilizador.

Contudo, se o pensamento de Durkheim explica a parte mais substancial da genealogia epistemológica do que veio a ser a obra de Gernet, não é explicação suficiente para o conjunto da obra, nem para o perfil de seu legado. A rigidez do modelo analítico de Durkheim foi superada por Gernet, na forma original como combinou sua sociologia à semântica histórica de Meillet e à psicologia histórica de Meyerson. Mas, em meio a esse quadro teórico finamente aplicado na leitura erudita dos textos gregos, pesou também algo de muito pessoal do seu humanismo, do engajamento político, do espírito público, livre e tolerante, todos muito próprios à personalidade de Gernet, marcada ainda, em sua vida acadêmica, pela discrição, persistência, generosidade e compromisso institucional, seja no cargo de decano de faculdade, seja na função de editor de periódicos científicos. Isso faz da Antropologia histórica de Gernet uma disciplina que associa o rigor e perspicácia a uma sensibilidade muito aguçada. 


\section{REFERÊNCIAS}

CAMP II, John McK (Ed.). The Athenian Agora. A Guide to the Excavations and Museum. 4. ed. Atenas: American School of Classical Studies at Athens, 1990.

CORRÊEA, Denis Renan. A “história das palavras” de Louis Gernet. In: Seminário Nacional de História da Historiografia: Tempo Presente \& Usos do Passado, 4., 2010, Ouro Preto. Caderno de resumos \& Anais... Ouro Preto: EdUFOP, 2010. p. 1-11. Disponível em: https:/ / www.academia.edu/1086346/A_hist\%C3\%B3ria_das_palavras_de_Louis_Gernet. Acesso em: 18 mar. 2019.

DAVIDOVITCH, André. In Memoriam: Louis Gernet (1882-1962). Revue française de sociologie, v. 3, n. 3, p. 329, juil.-sept., 1962. Disponível em: https://www.persee.fr/doc/ rfsoc_0035-2969_1962_num_3_3_6102. Acesso em: 19 mar. 2019.

DONATO, Riccardo di. L'anthropologie historique de Louis Gernet. Annales. Economie, sociétés, civilisations, v. 37, n. 5-6, p. 984-96, 1982.

DONATO, Riccardo di. Une oeuvre, un itinéraire (posface). In: GERNET, Louis. Les grecs sans miracles (textes 1903-1960, réunis par Riccardo di Donato). Paris: La Découverte-Maspero, 1983, p. 403-20.

DURKHEIM, Émile. As formas elementares da vida religiosa (o sistema totêmico na Austrália). São Paulo: Paulinas, 1989.

GAGNON-ARGUIN, L. Os arquivos, os arquivistas e a arquivística: considerações históricas. Lisboa: Dom Quixote, 1998.

GERNET, Louis. Recherches sur le développement de la pensée juridique et morale en Grèce. Étude Sémantique. Paris: Ernest Leroux, 1917.

GERNET, Louis. Anthropologie de la Grèce antique. Paris: François Maspero, 1968.

GERNET, Louis. Droit et institutions en Grèce antique. Paris: Flammarion, 1982.

GERNET, Louis. Les nobles dans la Gréce Antique. In: Droit et institutions en Grèce antique. Paris: Flammarion, 1982a, p. 215-28.

GERNET, Louis. Droit et ville dans l'Antiquité grecque. In: . Droit et institutions en Grèce antique. Paris: Flammarion, 1982b, p. 265-78.

GERNET, Louis. Les grecs sans miracles (textes 1903-1960, réunis par Riccardo di Donato). Prefácio de Jean-Pierre Vernant, posfácio de Riccardo di Donato. Paris: La Découverte-Maspero, 1983.

GERNET, Louis. Constitution et religion. In: Les grecs sans miracles (textes 1903-1960, réunis par Riccardo di Donato). Paris: La Découverte-Maspero, 1983a, p. 58-61.

GERNET, Louis. Les bases de la cité classique. In: . Les grecs sans miracles (textes $1903-$ 1960, réunis par Riccardo di Donato). Paris: La Découverte-Maspero, 1983b, p. 66-9. 
GERNET, Louis. La notion de démocratie chez les Grecs. In: Les grecs sans miracles (textes 1903-1960, réunis par Riccardo di Donato). Paris: La Découverte-Maspero, 1983c, p. 272-80. GERNET, Louis. Le droit pénal public à Athènes. In: Les grecs sans miracles (textes 1903-1960, réunis par Riccardo di Donato). Paris: La Découverte-Maspero, 1983d, p. 293-94.

GERNET, Louis; BOULANGER, André. Le génie grec dans la religion. Paris: Albin Michel, 1970 (1932). (L'Évolution de l'Humanité).

HUMPHREYS, Sally. The work of Louis Gernet. History and Theory, v. 10, p. 172-196, maio, 1971.

LE GOFF, Jacques. Prefácio. In: BLOCH, Marc. Os Reis taumaturgos. São Paulo: Cia. das Letras, 1993.

LÉVI-STRAUSS, Claude. Introdução: História e Etnologia. In: . Antropologia Estrutural. Rio de Janeiro: Tempo Brasileiro, 1985, p. 13-41.

MARETT, R. R. Preface. EVANS, Arthur et al. Anthropology and the Classics. Oxford: Clarendon Press, 1908, p. 3-6.

MAUSS, Marcel. Ensaio sobre a Dádiva. Forma e razão da troca nas sociedades arcaicas. In: . Sociologia e Antropologia. São Paulo: EDUSP, 1974, p. 37-184.

VERNANT, Jean-Pierrre. Préface. In: GERNET, Louis. Les grecs sans miracles (textes 1903-1960, réunis par Riccardo di Donato). Paris: La Découverte-Maspero, 1983, p. 7-13. 